\title{
The sandfly fauna, anthropophily and the seasonal activities of Pintomyia spinicrassa (Diptera: Psychodidae: Phlebotominae) in a focus of cutaneous leishmaniasis in northeastern Colombia
}

\author{
Fredy Galvis Ovallos ${ }^{1 /+}$, Yanis Ricardo Espinosa Silva ${ }^{2}$, Nelson Fernandez ${ }^{3}$, \\ Reynaldo Gutierrez ${ }^{3}$, Eunice Aparecida Bianchi Galati', Claudia Magaly Sandoval ${ }^{3}$
}

\begin{abstract}
'Departamento de Epidemiologia, Faculdade de Saúde Pública, Universidade de São Paulo, São Paulo, SP, Brasil 'Instituto de Física de Líquidos y Sistemas Biológicos, Universidad Nacional de La Plata, Buenos Aires, Argentina ${ }^{3}$ Laboratorio de Entomología Médica, Instituto de Investigación en Ciencias Biomédicas, Universidad de Pamplona, Pamplona, Norte de Santander, Colombia
\end{abstract}

This study was conducted to identify the sandfly fauna and the anthropophilic species in a coffee-growing area of Villanueva, Norte de Santander, Colombia, a focus of American cutaneous leishmaniasis, and to analyse the relationship between the most frequent species and rainfall, relative humidity and temperature, with the aim of contributing to epidemiological surveillance in the area. Sandfly collections were performed fortnightly between February 2006-September 2007 using automatic light traps, Shannon traps, protected human bait and aspiration in resting places. A total of 7,051 sandflies belonging to 12 species were captured. Pintomyia spinicrassa (95.7\%) predominated. Pintomyia oresbia and Lutzomyia sp. of Pichinde were found in the state of Norte de Santander for the first time. Pi. spinicrassa, Pintomyia nuneztovari, Micropygomyia venezuelensis, Lutzomyia (Helcocyrtomyia) scorzai and Lu. (Helcocyrtomyia) sp. were captured on the protected human bait. A significant association between $\mathrm{Pi}$. spinicrassa abundance and the total rainfall and the average temperature and humidity 10 days before the collection was observed. The dominance of $\mathrm{Pi}$. spinicrassa, a recognised vector of Leishmania braziliensis, especially during the dry periods, indicates that the risk of parasite transmission may increase.

Key words: Phlebotominae - Pintomyia spinicrassa - vector ecology - leishmaniasis

Leishmaniasis are considered to be re-emerging diseases of great significance to public health due to the severity of their clinical manifestations. In Colombia, during the period 2006-2011, 62,843 cases of American cutaneous leishmaniasis (ACL) were reported, with an annual average rate of 8,926 new cases (INS 2012). Currently, 148 species of Lutzomyia (Bejarano 2006, Ferro et al. 2011) are known to exist in Colombia, six of which are recognised as vectors of leishmaniasis agents. Among the species of sandflies registered in Colombia, the species grouped in the townsendi series Pintomyia (Pifanomyia) (Galati 2003) of the Andean Region are epidemiologically relevant due to their involvement in the transmission of agents of ACL and human bartonellosis (Bejarano et al. 2003, Cohnstaedt et al. 2011).

The Leishmania species most frequently related to ACL is Leishmania (Viannia) panamensis, followed by Leishmania (Viannia) braziliensis, which has the most extensive geographical distribution in Colombia, especially in coffee-growing areas (Corredor et al. 1990).

In the northeastern region of Colombia, the state of Norte de Santander (NS) (Fig. 1) is a mesoendemic area for ACL; in the past seven years, 1,524 cases of cutaneous leishmaniasis have been registered there. Cardenas

+Corresponding author: fgalvis@usp.br

Received 12 August 2012

Accepted 12 November 2012 et al. (2006) reported that the increase in the number of cases is associated with the climatic fluctuations caused by the El Niño Southern Oscillation (ENSO), which affect the sandfly population.

The main objective of this study was to describe the sandfly fauna in Villanueva, where there is active transmission of ACL in a coffee-growing area in NS. This study also sought to identify the anthropophilic species and their endophagic habits and to analyse the relationships between the most frequent species and the rainfall regime, relative humidity and temperature, with the aim of contributing to epidemiological surveillance in this transmission area.

\section{MATERIALS AND METHODS}

Area of study - The municipality of Gramalote is located in the central region of NS. The urban area was obliterated in 2011 by a natural landslide; it was located between $7^{\circ} 50^{\prime} 8^{\circ} 3^{\prime} \mathrm{N}-72^{\circ} 45^{\prime} 72^{\circ} 55^{\prime} \mathrm{W}$. The population of the municipality was estimated at 7,964 inhabitants in 2005 and the local economy is based on coffee and cattle (CORPONOR 2012). The climate in Gramalote includes two dry seasons, one from January-February and the other from July-September, that are interspersed with rainy seasons, representing a typical bi-modal pattern. The annual averages are $23^{\circ} \mathrm{C}$ for temperature, $2,500 \mathrm{~mm}$ for rainfall and $80 \%$ for relative humidity.

Collection sites - Three houses, one on each of three farms (Buenavista, El Almendro and Villa-Antigua), were selected in the Villanueva neighbourhood, a typical coffee-growing region located between 1,300-1,650 
masl. This region is characterised as premontane rainforest (CORPONOR 2012). The criteria for the selection of the houses were the notification of confirmed ACL cases and a previous verbal agreement with the owners.

Sandfly collections - The sandfly captures were performed at fortnightly intervals between February 2006October 2007 with Shannon and automatic light traps, human bait and collection in resting places.

Shannon traps - The trap was operated by a person using a Castro aspirator and a flashlight on two successive nights at fortnightly intervals, from 07.00 pm-09.00 $\mathrm{pm}$, in the peridomicile area (a coffee plantation) on Buenavista farm from February 2006-February 2007.

Protected human bait - Simultaneously with the operation of the Shannon trap, also on Buenavista farm, flies landing on two researchers who were clothed in dark pants and long-sleeved shirts and who were stationed in the intra and peridomicile areas were captured using a Castro aspirator and a flashlight.

Resting places - Collections were also performed among the rocks found on the coffee plantations and on the trunks of the interspersed trees on two successive days fortnightly from February 2006-February 2007. The collections were performed between 02:00 pm-04:00 pm using a Castro aspirator.

Automatic light traps - The three selected houses were all sampled. One CDC-type automatic light trap was placed indoors (bedroom) and another in the peridomicile area (coffee plantation). The traps were located $1.5 \mathrm{~m}$ above the ground and $25 \mathrm{~m}$ apart. The collections were performed fortnightly between October 2006-September 2007 on two successive nights from 06:00 pm to 06:00 am. In January and February 2007, two traps were installed in the forest $3 \mathrm{~km}$ from Buenavista farm for one night.

The specimens collected were preserved in $70 \%$ alcohol and taken to the Laboratory of Medical Entomology of the Biomedical Sciences Institute of Pamplona

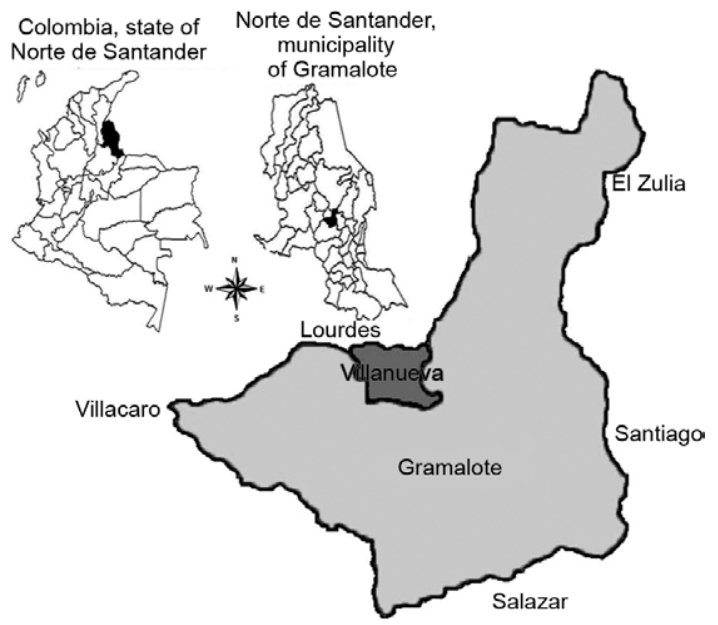

Fig. 1: study area: Villanueva, municipality of Gramalote, Norte de Santander, Colombia.
University, Pamplona (NS) for identification and slide mounting. The identification was performed according to Galati's (2003) classification and the species name abbreviations follow Marcondes (2007).

The climatic data for temperature, relative humidity and rainfall were obtained from climatological station 1602503 of the Instituto de Hidrología, Metereología y Estudios Ambientales (ideam.gov.com), Colombia, located at $07^{\circ} 47 \mathrm{~N} 72^{\circ} 49 \mathrm{~W}, 860$ masl.

The frequencies of the most abundant species were calculated according to Williams' average (Haddow 1960). A Spearman test (PASW v.17) was used to analyse the strength of the correlations between the most abundant species and several climatic parameters: total rainfall, the average temperatures and humidities for the 15 and 10 days prior to the capture date and the temperature and humidity on the day of the collection. A Mann-Whitney $U$ test was used to compare the frequencies in the intra and peridomicile areas.

\section{RESULTS}

The number of sandflies captured for each species, according to the collection method and collection site, is presented in Table I.

The phlebotomine fauna was represented by 12 species: Evandromyia (Aldamyia) dubitans (Sherlock, 1962), Lutzomyia (Helcocyrtomyia) hartmanni (Fairchild \& Hertig, 1957), Lutzomyia (Helcocyrtomyia) scorzai (Ortiz, 1965), Lu. (Hel.) sp., Lu. (Hel.) sp. of Pichinde Young 1979, Micropygomyia (Sauromyia) venezuelensis (Floch \& Abonnenc, 1948), Psathyromyia (Psathyromyia) shannoni (Dyar, 1929), Pintomyia (Pifanomyia) nuneztovari (Ortiz, 1964), Pintomyia (Pifanomyia) oresbia (Fairchild $\&$ Hertig, 1961), Pintomyia (Pifanomyia) sauroida (Osorno-Mesa, Morales \& Osorno, 1972), Pintomyia (Pifanomyia) serrana (Damasceno \& Arouck, 1949) and Pintomyia (Pifanomyia) spinicrassa (Morales, Osorno-Mesa, Osorno \& Hoyos, 1969). Pi. spinicrassa was the most frequent species (95.7\%) and was predominant for all the collection methods used and at all the sites sampled.

In the captures using protected human bait, five anthropophilic species were identified: Pi. spinicrassa, $P i$. nuneztovari, Mi. venezuelensis, Lu. scorzai and Lu. (Hel.) $\mathrm{sp}$. These species were collected in peridomicile and intradomicile areas, a result that could suggest an endophagic habit. The highest frequencies obtained using human bait were for $P i$. spinicrassa in the peridomicile area.

In addition to Pi. spinicrassa and Pi. nuneztovari, specimens of the subgenus Helcocyrtomyia and a female of Pi. oresbia were collected using the Shannon trap. Ev. dubitans, Pi. serrana and Pa. shannoni were only attracted by the automatic light traps. Twenty-four females of Pi. spinicrassa and one of Mi. venezuelensis were collected from resting places on rocks.

The frequency of Pi. spinicrassa collected with protected human bait was higher in the peridomicile area than in the intradomicile area $(p<0.003)$, whereas the highest frequencies found for the automatic light trap (CDC) collections were observed in the intradomicile area $(p<0.014)$. The highest Williams' average (11.5 insects/trap) was obtained for the forest, followed by the 


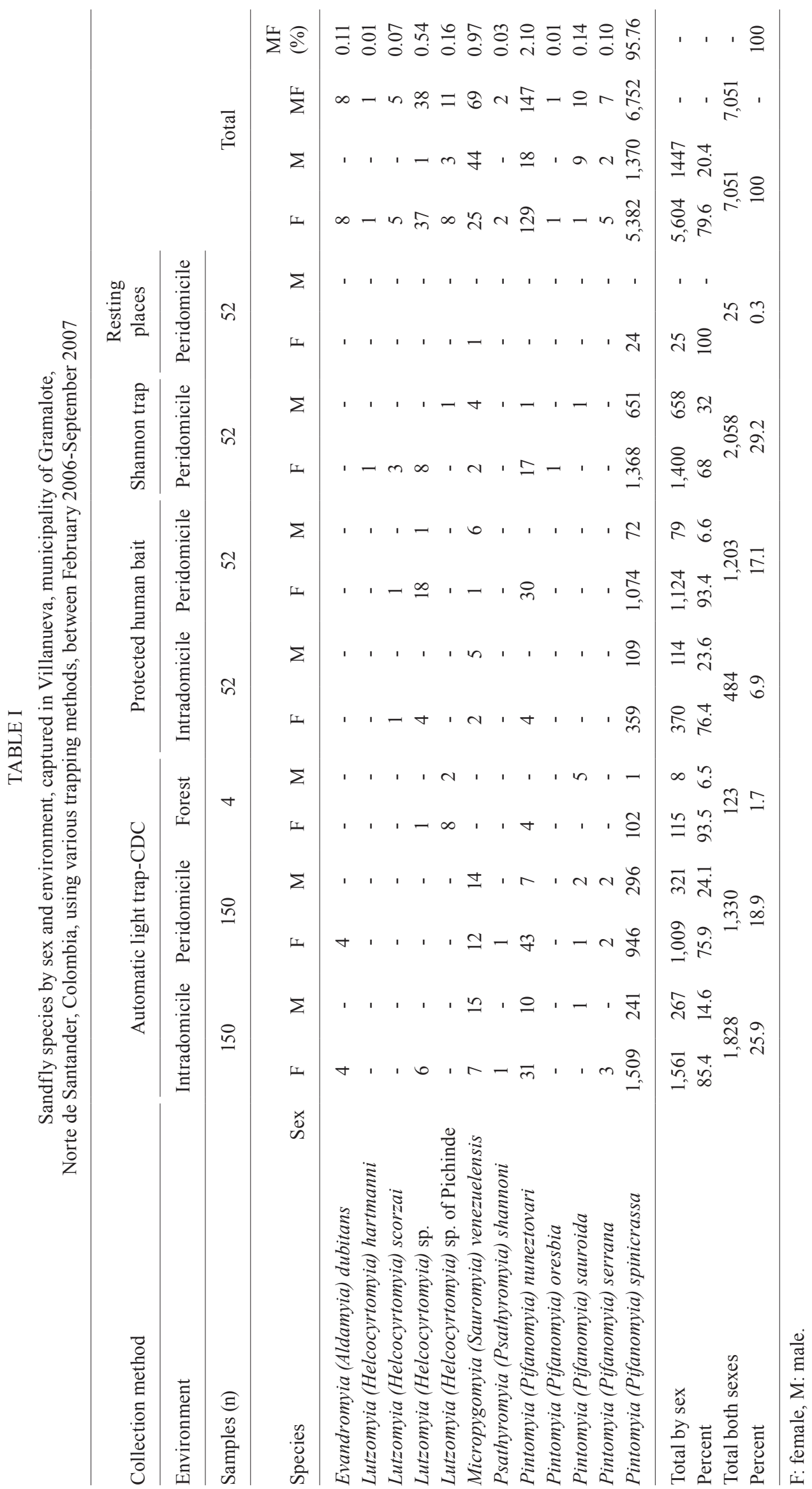


Shannon trap (10.7 insects/trap) and protected human bait in the peridomicile area (9.9 insects/person). More females than males were captured by all the sampling methods. The lowest sex ratio (female/male) was obtained using the Shannon traps (2.0:1.0) and the highest was obtained in the forest using automatic light traps (102:1.0) (Table II).

The monthly frequency of Pi. spinicrassa collection by sampling method is presented in Figs 2, 3. The protected human bait gave the highest abundances during the dry periods (1st: January-February; 2nd: July-September), but lower abundances during the rainy periods (1st: MarchJune; 2nd: October-December). The highest abundance during the first dry period was observed in the intradomicile area. During the second dry period, the highest abundance was observed in the peridomicile area (Fig. 2). The highest frequencies found in the Shannon trap collections occurred throughout the second dry period in 2006 and the peak was observed in February 2007. For the automatic light trap, the peak of abundance was observed in the dry periods for both the intra and peridomicile areas.

The values of $r$ and $p$ obtained in the tests of the correlations between the abundance of Pi. spinicrassa and rainfall, temperature and relative humidity 10 days before the captures are presented in Table III. The correlation analysis showed a significant negative correlation between the abundances of this species collected using human bait (intra and peridomicile areas) and Shannon traps and the relative humidity. This analysis also revealed the same pattern for protected human bait and rainfall; however, the correlations between the abundances of flies collected using protected human bait (peridomicile) and Shannon traps and temperature were significant and positive. Non-significant correlations were observed between the abundance of Pi. spinicrassa and the rainfall, temperature and relative humidity 15 days before collection and on the collection day.

\section{DISCUSSION}

Pi. spinicrassa predominated among the 12 species identified in Villanueva, Gramalote. In this study, specimens of Evandromyia walkeri (Newstead, 1914), Pintomyia pia (Fairchild \& Hertig, 1961), Pintomyia ovallesi (Ortiz, 1952), Lutzomyia lichyi (Floch \& Abonnenc, 1950), Lutzomyia gomezi (Nitzulescu, 1931), Trichopygomyia ferroae (Young \& Morales, 1987) and Lutzomyia erwindonaldoi (Ortiz, 1978), found in a previous study (Alexander et al. 2001), were not collected. These differences in the faunal composition in Gramalote may be related to differences between the collection sites, given the variations in altitude in the northeastern Andean cordillera. With the identification of the Villanueva fauna, 19 species of sandfly have been identified in Gramalote, NS; the species Pi. oresbia and Lutzomyia sp. of Pichinde were recorded in this state for the first time.

Among the species collected on protected human bait, two species, $P i$. spinicrassa, which has been found naturally infected with $L$. (V.) braziliensis and Pi. nuneztovari, which is susceptible to infection by this parasite under laboratory conditions (Young et al. 1987, Santamaria et al. 1999), should be highlighted. In terms of the eco-epidemiology of ACL, our results indicate that $P i$. spinicrassa plays an important role in the transmission of Leishmania sp. in the coffee-growing areas of Gramalote in view of this species' high frequencies, anthropophilic habits and endophagic behaviour. An important role of Pi. spinicrassa was also observed by Alexander et al. (2009) in other localities in NS. In addition, this species has been found naturally infected by $L$. ( $\mathrm{V}$.) braziliensis in the coffee-growing regions of Colombia and Venezuela (Young et al. 1987, Perruolo et al. 2006).

The low frequencies of the other species of the subgenera Pifanomyia and Helcocyrtomyia may indicate their lesser importance in the transmission of Leishma-

TABLE II

Distribution of Pintomyia spinicrassa by site, method and environment, collected in Villanueva, municipality of Gramalote, Norte de Santander, Colombia, between February 2006-September 2007

\begin{tabular}{|c|c|c|c|c|c|c|}
\hline Site & Method & Environment & $\begin{array}{c}\mathrm{F} \\
\mathrm{n}(\%)\end{array}$ & $\begin{array}{c}M \\
\mathrm{n}(\%)\end{array}$ & $\mathrm{F} / \mathrm{M}$ ratio & $\begin{array}{c}\text { William's } \\
\text { average }\end{array}$ \\
\hline \multirow[t]{7}{*}{ Buenavista farm } & \multirow[t]{2}{*}{ Human bait } & Intradomicile & $359(76.7)$ & $109(23.3)$ & $3.3: 1.0$ & 2.5 \\
\hline & & Peridomicile & $1074(93.7)$ & $72(6.3)$ & 14.9:1.0 & 9.9 \\
\hline & \multirow{2}{*}{$\begin{array}{l}\text { Shannon trap } \\
\text { resting places }\end{array}$} & Peridomicile & $1368(67.8)$ & $651(32.2)$ & $2.1: 1.0$ & 10.7 \\
\hline & & Peridomicile & $25(100)$ & - & - & 0.2 \\
\hline & \multirow[t]{3}{*}{$\mathrm{CDC}$} & Forest & $102(99)$ & $1(1)$ & 102.0:1.0 & 11.5 \\
\hline & & Intradomicile & $1509(86.2)$ & $241(13.8)$ & 6.3:1.0 & 3.5 \\
\hline & & Peridomicile & $946(76.2)$ & $296(23.8)$ & $3.2: 1.0$ & 2 \\
\hline \multirow[t]{2}{*}{ El Almendro farm } & \multirow[t]{2}{*}{$\mathrm{CDC}$} & Intradomicile & $392(87.3)$ & $57(12.7)$ & $6.9: 1.0$ & 4.1 \\
\hline & & Peridomicile & $325(82.5)$ & $69(17.5)$ & $4.7: 1.0$ & 1.8 \\
\hline \multirow[t]{2}{*}{ Villa-Antigua farm } & \multirow[t]{2}{*}{$\mathrm{CDC}$} & Intradomicile & $117(76)$ & $37(24)$ & $3.2: 1.0$ & 1.4 \\
\hline & & Peridomicile & $147(77.3)$ & $43(22.7)$ & $3.4: 1.0$ & 1.2 \\
\hline
\end{tabular}

F: female; M: male. 
nia in the study area. However, the capture of specimens of Lutzomyia sp. of Pichinde, a species not yet formally described in NS expands the knowledge of its geographical distribution. Further, the presence of this taxon in this region, in sympatry with $L u$. scorzai and other species of the subgenus Helcocyrtomyia, may provide data to elucidate the taxonomy of Lutzomyia sp. of Pichinde.

For the captures made on protected human bait, the high frequencies in the peridomicile area can be explained by these species' close contact with the host (the natural shelters of these females are close to the capture area). Although the highest Williams' average and sex ratio (female/male) were obtained in the forest (Table II), these values could have been influenced by the period and the number of collections made (only 1, during the dry season). The similarity between the Williams' averages for the Shannon trap (10.7 insects/trap) and for the protected human bait in the peridomicile area $(9.4$

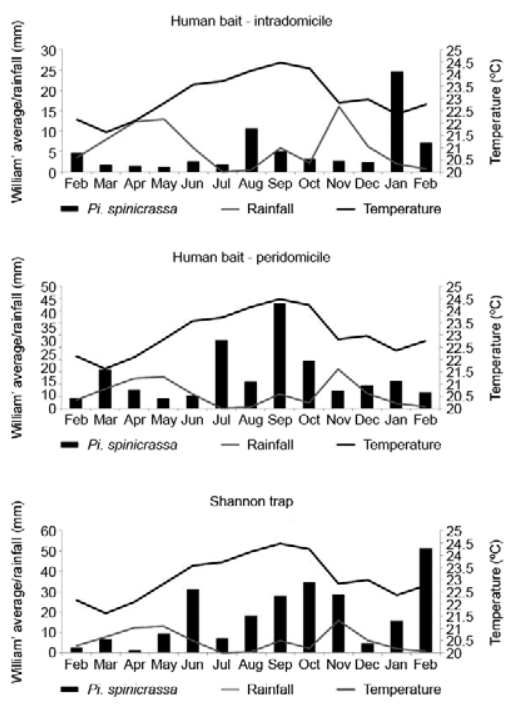

Fig. 2: monthly abundance of Pintomyia spinicrassa captured with protected human bait in intradomicile and peridomicile and Shannon trap from February 2006-February 2007. insects/person) is reasonable because the two collections were performed in the same environment and because the presence of humans was required by both methods. The high frequencies observed in the automatic light traps in the intradomicile area suggest endophagic behaviour and a high risk of infection due to Leishmania sp. in this environment; therefore, the use of mosquito nets could have an important role as a prophylactic method in this region. Of the species captured on human bait, only $\mathrm{Mi}$. venezuelensis does not appear to be anthropophilic because the number of males collected was greater than the number of females. In fact, the females of this species feed on reptiles (Young \& Duncan 1994).

The abundance and monthly distribution of Pi. spinicrassa in Gramalote show that this species predominates in the dry periods. These results differ from those of Alexander et al. (1992) obtained on coffee plantations in the municipality of Arboledas, where high frequencies were observed during the rainy seasons. The differences between the results of these two contrasting studies are reasonable because the captures in Arboledas were made in resting places, where the sandflies tend to remain sheltered during the rainy seasons. Moreover, high abundances of Pi. spinicrassa during the dry season have been

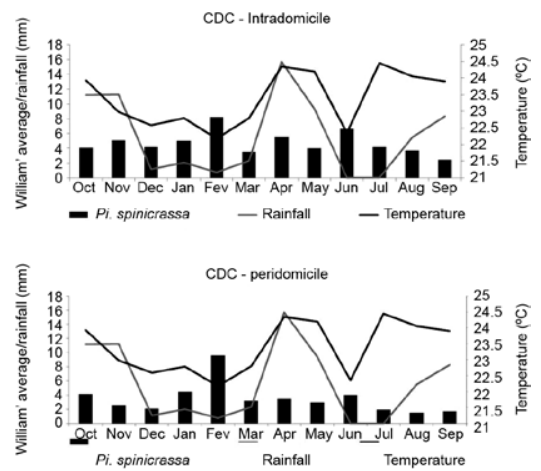

Fig. 3: monthly abundance of Pintomyia spinicrassa captured with automatic light traps (CDC) in intradomicile and peridomicile from October 2006-September 2007.

TABLE III

Spearman correlation values between the abundance of Pintomyia spinicrassa and the average rainfall, temperature and relative humidity 10 days before the collections in Villanueva, municipality of Gramalote Norte de Santander, Colombia

\begin{tabular}{|c|c|c|c|c|c|c|}
\hline \multirow[b]{2}{*}{ Method/environment } & \multicolumn{2}{|c|}{ Rainfall } & \multicolumn{2}{|c|}{ Humidity } & \multicolumn{2}{|c|}{ Temperature } \\
\hline & $\mathrm{r}$ & $\mathrm{p}$ & $\mathrm{r}$ & $\mathrm{p}$ & $\mathrm{r}$ & $\mathrm{p}$ \\
\hline Human bait/intradomicile & -0.48 & $0.01^{a}$ & -0.52 & $0.01^{a}$ & 0.06 & 0.78 \\
\hline Human bait/peridomicile & -0.19 & 0.36 & -0.39 & 0.05 & 0.43 & $0.03^{a}$ \\
\hline Shannon trap/peridomicile & -0.01 & 0.95 & -0.53 & $0.01^{a}$ & 0.50 & $0.01^{a}$ \\
\hline CDC/intradomicile & 0.00 & 0.9 & -0.15 & 0.49 & 0.36 & 0.10 \\
\hline $\mathrm{CDC} /$ peridomicile & -0.30 & 0.16 & -0.22 & 0.31 & -0.18 & 0.40 \\
\hline
\end{tabular}

$a$ : values statistically significant; $b$ : value not absolute zero. 
described in an endemic area of the Venezuelan Andes (Perruolo 2004). Recently, Ferro et al. (2011) described a similar distribution of Pintomyia longiflocosa (townsendi series) in the Andean region of Colombia. Thus, our observations in NS indicate that the dry seasons are periods of great risk of ACL transmission given the more intense activity of the anthropophilic species of the townsendi series, particularly Pi. spinicrassa, a suspected vector of L. (V.) braziliensis, during these periods.

The dynamics of the diseases transmitted by vectors are influenced by the weather, other natural phenomena and human activities, all of which affect the vectors, parasite reservoirs and blood sources (Patz et al. 2000). Thus, knowledge of the seasonal distribution of insect vectors and the relationship between this distribution and climatic variables are important tools in entomological surveillance, providing the information necessary for the development of prevention and control measures. Analysis of the correlation between the climatic variables and the $P i$. spinicrassa frequencies revealed that the relative humidity (closely related to the rainfall) limits the density of the sandfly population in this region. Further, an increase in the temperature led directly to an increase in the density of Pi. spinicrassa, which might intensify the vectorial capacity of this species during the hot and dry periods of the year. These findings are consistent with the continuous occurrence of El Niño during the study period, from $\mathrm{Au}-$ gust 2006-January 2007, including the entire dry season from mid-year (NOAA 2010) on. Our results are in agreement with those of Cardenas et al. (2006), who observed an increase in the number of ACL cases during the ENSO events in NS, Colombia, which are characterised by a decrease in rainfall and a lengthening of the dry periods with an increase in temperature. These temperature and rainfall changes could decrease the duration of the immature stages and lead to an increase in the adult sandfly population (Endris \& Young 1984), thus reducing the duration of the gonotrophic cycle and the extrinsic incubation period of the parasite (Meyer 1989), both of which are important factors in the transmission of parasites.

\section{REFERENCES}

Alexander B, Agudelo L, Navarro F, Ruiz F, Molina J, Aguilera G, Quiñones L 2001. Phlebotomine sandflies and leishmaniasis risks in Colombian coffee plantations under two systems of cultivation. Med Vet Entomol 15: 364-373.

Alexander B, Agudelo L, Navarro J, Ruiz J, Molina J, Aguilera G, Klein A, Quiñones M 2009. Relationship between coffee cultivation practices in Colombia and exposure to infection with Leishmania. Trans R Soc Trop Med Hyg 103: 1263-1268.

Alexander B, Ferro C, Young DG, Morales A, Tesh RB 1992. Ecology of phlebotomine sand flies (Diptera: Psychodidae) in a focus of Leishmania (Viannia) braziliensis in Northeastern Colombia. Mem Inst Oswaldo Cruz 87: 387-395.

Bejarano EE 2006. Lista actualizada de los psicódidos (Diptera: Psychodidae) de Colombia. Folia Entomol Mex 45: 47-56.

Bejarano EE, Rojas W, Uribe S, Vélez ID 2003. Systematics of the Lutzomyia species of the verrucarum Theodor group, 1965 (Diptera: Psychodiadae). Biomedica 23: 87-102.

Cardenas R, Sandoval CM, Rodríguez-Morales AJ, Franco-Paredes C 2006. Impact of climate variability in the occurrence of leish- maniasis in northeastern Colombia. Am J Trop Med Hyg 75: 273-277.

Cohnstaedt LW, Beati L, Caceres AG, Ferro C, Munstermann LE 2011. Phylogenetics of the phlebotomine sand fly group verrucarum (Diptera: Psychodidae: Lutzomyia). Am J Trop Med Hyg 84: 913-922.

CORPONOR - Corporación Autónoma Regional de la Frontera Nororiental 2012. Plan de ordenamiento territorial. Municipio de Gramalote. Available from: corponor.gov.co.

Corredor A, Kreutzer RD, Tesh RB, Boshell J, Palau MT, Cáceres E 1990. Distribution and etiology of leishmaniasis in Colombia. Am J Trop Med Hyg 42: 206-214.

Endris RG, Young DG 1984. The laboratory biology of the sand fly Lutzomyia anthophora (Diptera: Psychodidae). J Med Entomol 21: 656-664.

Ferro C, Marín D, Góngora R, Carrasquilla MC, Trujillo JE, Rueda NK, Marín J, Valderrama-Ardila C, Alexander N, Pérez M, Munstermann LE, Ocampo CB 2011. Phlebotomine vector ecology in the domestic transmission of American cutaneous leishmaniasis in Chaparral, Colombia. Am J Trop Med Hyg 85: 847-856.

Galati EAB 2003. Classificação de Phlebotominae. In EF Rangel, R Lainson, Flebotomíneos do Brasil, Fiocruz, Rio de Janeiro, p. 23-51.

Haddow AJ 1960. Studies on the biting-habits and medical importance of East African mosquitos in the genus Aedes. I. Subgenera Aedimorphus, Banksinella and Nunnius. Bull Entomol Res 50: 759-779.

INS - Instituto Nacional de Salud 2012. Estadísticas de la vigilancia en Salud Pública. Vigilancia rutinaria. Avaliable from: ins.gov.co.

Marcondes CB 2007. A proposal of generic and subgeneric abbreviations for phlebotomine sandflies (Diptera: Psychodidae: Phlebotominae) of the world. Entomol News 118: 351-356.

Meyer RP 1989. Estimation of vectorial capacity: pathogen extrinsic incubation and vector competence. Bull Soc Vector Ecol 14: 60-66.

NOAA 2010. Climate prediction center/NCEP. ENSO cycle: recent evolution, current status and predictions. Available from: cpc. ncep.noaa.gov/products/analysis_monitoring/lanina/enso_evolution-status-fcsts-web.pdf.

Patz JA, Graczyk TK, Geller N, Vittor AY 2000. Effects of environmental change on emerging parasitic diseases. Int J Parasitol 30: 1395-1405.

Perruolo G 2004. Aspectos ecológicos de Lutzomyia spp (Diptera: Psychodidae) en un foco endémico de leishmaniasis cutanea en el estado Tachira, Venezuela. Bol Mal Salud Amb 44: 35-44.

Perruolo G, Noris Rodríguez N, Feliciangeli MD 2006. Isolation of Leishmania (Viannia) braziliensis from Lutzomyia spinicrassa (species group verrucarum) Morales Osorno Mesa, Osorno and Hoyos 1969, in the Venezuelan Andean region. Parasite 13: 17-22.

Santamaria E, Castillo M, Cardenas R, Bello F, Ayala M, Ferro C 1999. Competência vectorial de las espécies de Lutzomyia del Grupo verrucarum (Diptera: Psychodidae) en un foco endémico de Leishmania braziliensis en Reventones, Cundinamarca. Biomedica 19: 115-126.

Young DG, Duncan MA 1994. Guide to the identification and geographic distribution of Lutzomyia sand flies in Mexico, the West Indies, Central and South America (Diptera: Psychodidae). Mem Amer Ent Inst 54: 881.

Young DG, Morales A, Kreutzer RD, Alexander JB, Corredor A, Tesh RB 1987. Isolations of Leishmania braziliensis (Kinetoplastida: Trypanosomatidae) from cryopreserved Colombian sand flies (Diptera: Psychodidae). J Med Entomol 24: 587-589. 